\title{
STRATEGI MELAYANI UNREACHED PEOPLE GROUPS BERDASARKAN KAJIAN EKSEGETIS 1KORINTUS 9: 19-23
}

\author{
Samuel Purdaryanto \\ Sekolah Tinggi Teologi Arastamar Bengkulu \\ samuelpurdaryanto@gmail.com
}

\begin{abstract}
This theme discusses the exegetical study of contextual evangelism in 1 Corinthians 9: 19-23. Contextual evangelism has always been an interesting topic in discussions of Missiology and Ecclesiology. Although sometimes controversy, contextual evangelism is still one of the effective methods of preaching the gospel to the neglected tribes. The preaching of the cross-cultural gospel was one of the points Paul talked about with the church in the city of Corinth. The Apostle Paul said that preaching the gospel was a must for him (1 Corinthians 9:16). And in chapters 9: 19-23 the apostle Paul tells how the method or method he used to preach the gospel to those who are culturally different from himself. Gospel preaching is a mandate or the Great Commission given by the Lord Jesus to believers, and must be preached to all tribes and languages. In preaching the Gospel, Paul sets an example that is a strategy in contextual evangelism. The Apostle Paul willingly devoted himself "I made myself a servant, 1 Corinthians 9:19." Paul also adjusted to be able to understand those of different cultures "by becoming like". So you can win as much as possible. As well as a strong vision to win as many people as possible for Christ, so that they become saved. Paul understood the mandate given, to make Jews and non-Jews to be mursed Christ. Challenges and obstacles in preaching Inil are always there, but understanding methods based on God's word is the choice to get rid of these obstacles.
\end{abstract}

Keywords: Serve, Adjust, Win

Abstraksi: Tema ini membahas mengenai kajian eksegesis tentang penginjilan kontekstual dalam 1 Korintus 9: 19-23. Penginjilan kontekstual selalu menjadi topik yang menarik dalam diskusi Misiologi dan Eklesiologi. Meskipun terkadang kontroversi, penginjilan kontekstual masih menjadi salah satu metode efektif dalam memberitakan injil kepada suku terabaikan. Pemberitaan injil lintas budaya merupakan satu pokok yang dibicarakan oleh Paulus kepada jemaat di kota Korintus. Rasul Paulus mengatakan bahwa memberitakan injil merupakan suatu keharusan bagi dirinya (1Korintus 9: 16). Dan pada pasal 9: 19-23 rasul Paulus menyampaikan bagaimana cara atau metode yang dia lakukan untuk memberitakan Injil kepada mereka yang berbeda budaya dengan dirinya. Pemberitaan Injil merupkan mandat atau Amanat agung yang diberikan Tuhan Yesus kepada orang percaya, dan harus diberitakan kepada segala suku kaum dan bahasa. Dalam memberitakan Injil, Paulus memberikan teladan yang menjadi strategi dalam penginjilan kontekstual. Rasul Paulus rela menghambakan diri "aku menjadikan diriku hamba, 1 Korintus 9: 19. "Paulus juga menyesuaikan diri untuk dapat memahami mereka yang berbeda budaya "dengan menjadi seperti". Supaya dapat memenangkan sebanyak mungkin. Serta visi yang kuat untuk memenangkan orang sebanyak mungkin bagi Kristus, sehingga mereka menjadi selamat. Paulus memahami mandat yang diberikan, untuk menjadikan orang Yahudi maupun orang non Yahudi untuk dijadikan muri Kristus. Tantangan dan hambatan dalam memberitakan Inil selalu ada, namun memahami metode berdasarkan firman Tuhan adalah pilihan untuk menyingkirkan hambatan tersebut.

Kata Kunci: Menghamba, Menyesuaikan diri, Memenangkan 


\section{PENDAHULUAN}

Setiap orang percaya mempunyai tanggung jawab untuk memberitakan Kabar Baik. Memberitakan Kabar Baik merupakan perintah dan Amanat Agung yang diberikan oleh Tuhan Yesus. Perintah-Nya yang tertulis dalam Matius 28: 18-20 untuk pergi dan menjadikan semua bangsa murid-Nya. Kata bangsa dari frasa 'semua bangsa' menggunakan kata Yunani č $\theta v \eta$ (etne), ${ }^{1}$ yang menunjuk kepada nation semua suku. Sangatlah jelas bahwa Tuhan Yesus memerintahkan untuk menjadikan semua orang dari setiap suku dan bahasa menjadi murid-Nya. Supaya berita Kristus sampai kepada setiap suku dan bangsa, makan Injil atau Kabar Keselamatan itu perlu disampaikan dalam budaya dan konteks setempat.

Penginjilan merupakan salah satu dari empat pilar gereja. Penginjilan adalah rancangan dan karya Allah yang menghimpun bagi diri-Nya suatu umat untuk bersekutu, menyembah dan melayani Dia secara utuh dan serasi. ${ }^{2}$ Sejak abad permulaan, perintah untuk memberitakan Injil merupakan perintah yang jelas, yang diberikan kepada setiap orang percaya. Seperti yang sudah diketahui secara umum "Injil” berasal dari istilah Yunani “Evanglion” yang berarti Kabar Baik. Akan tetapi kata tersebut hanya merujuk khusus Kabar Baik yang bersumber dari Allah. ${ }^{3}$ Dan Kabar Baik dari Allah itu harus disampaikan kepada setiap orang percaya agar menjadi murid Kristus. Frasa menjadikan murid, Wiersbe menjelaskan sebagai tugas besar untuk dilaksanakan, dan dimanapun orang percaya haruslah menjadi saksi. $^{4}$ Sehingga dapat dikatakan bahwa 2020.

1 Friberg, Bible Work, versi 8, CD ROM, Inggris, Analytical Greek Lexicon, t.t., diakses 4 Maret

2 Yakub Tomatala, Penginjilan Masa Kini 1 (Malang: Gandum Mas, 1997), 2.

3 Imanuel Sukardi, Berkat-Berkat Surat Roma (Surakarta: STT Berita Hidup, 2011), 23.

4 Warren W. Wiersbe, The Bible Exposition Commentary; An Exposition of The new Testament Comprising the Entire "BE" Series (Illionis: Victor Books, 1989). 
menjadikan semua bangsa murid Kristus berhimpun dan menyembah Dia merupakan tugas bagi semua orang percaya.

Upaya dalam menghimpun semua orang dari berbagai suku kaum dan bahasa bukanlah tugas yang mudah untuk dilakukan. Amanat agung yang Tuhan Yesus berikan sangat jelas yaitu; menjadikan semua etnis, semua suku sebagai murid Kristus, murid yang berhimpun menyembah Dia. Tugas dan mandat yang diberikan oleh Tuhan Yesus segera dilaksanakan oleh para murid-murid-Nya yang pertama. Alkitab juga mencatat bahwa Paulus memberitakan Injil dan menjadikan bangsa-bangsa non Yahudi murid Kristus. Paulus memenuhi mandat untuk menjadikan semua etnis, suku bangsa menjadi murid Kristus. Orang Roma, orang Yunani dan beberapa bangsa lain juga dibawa kepada Kristus.

Usaha Paulus untuk menjangkau orang-orang non Yahudi atau bangsabangsa lain terlihat dalam salah satu ungkapannya yang terdapat dalam 1Korintus 9: 20. Ungkapan "menjadi seperti" menunjukan bahwa Paulus berkontekstual atau menjadi sama dengan budaya orang setempat agar dapat memenangkan etnis tersebut. Hal yang sama dimana Tuhan Yesus pun harus menjadi sama dengan manusia untuk menyelamatkan manusia.

Menjalankan Amanat Agung untuk menjadikan semua bangsa murid Kristus adalah tugas panggilan yang harus dilaksanakan. Perlu hikmat Tuhan dan kuasa Roh Kudus untuk dapat menjangkau. Terkait tentang kuasa Roh Kudus dalam memberitakan berita injil, Waharman menulis, "seorang penginjil hendaknya mempercayai bahwa Roh Kudus sedang bekerja untuk mencapai 
tujuannya dalam hati mereka yang mendengarkan berita Injil."5 Penjangkauan kontekstual merupakan cara yang Allah berikan guna menjangkau setiap suku kaum dan bahasa. Sejak zaman para rasul hingga saat ini, amanat agung untuk menjadikan semua bangsa murid Kristus terus dikerjakan.Meskipun dalam pelaksanaannya masih belum maksimal.

Penginjilan kontekstual merupakan upaya yang telah dilakukan sejak zaman para rasul. Yohanes memperkenalkan Yesus sebagai logos yang menjadi manusia dan menyelamatkan kepada masyarakat helenis (Yoh. 1: 1-18). Dengan cara ini, orang Helenis dapat mengenal siapa Yesus. Istilah "kontekstualisasi" sendiri baru menjadi pokok kajian akademik sekitar tiga dekade, akhir abad 20 . Ada pun "kontekstualisasi" sendiri memiliki pengertian atau arti berhubungan dengan konteks. ${ }^{6}$ Rasid Rachman menuliskan:

Kontekstualisasi adalah usaha menempatkan sesuatu dalam konteksnya, sehingga tidak asing lagi, tetapi terjalin dan menyatu dengan keseluruhan seperti benang dalam tekstil. Dalam hal ini tidak hanya tradisi kebudayaan yang menentukan tetapi situasi dan kondisi sosial pun turut berbicara. ${ }^{7}$

Dalam kekristenan ada dua istilah yang terkait dengan kontekstual, namun beda maksudnya. Pertama, ada Teologia Kontekstual. Kedua, Penginjilan Kontekstual. Dalam penelitian ini, penulis akan fokus pada penelitian mengenai penginjilan kontekstual.

Istilah kontekstualisasi pertama kali dicetuskan oleh Aharon Sapaezian dan Shoki Coe, kepada direktur Theological Education Fund WCC pada tahun 1972. Karena menilai bahwa indegenisasi teologi (memaksa budaya lokal untuk

\footnotetext{
5 Waharman Waharman, "Studi Eksegetis Peranan Roh Kudus Dalam Penginjilan Berdasarkan Injil Yohanes 16:4b-15," Manna Rafflesia 6, no. 1 (31 Oktober 2019): 36-52, https://doi.org/10.38091/man_raf.v6i1.109.

${ }^{6}$ N N, "Kamus Besar Bahasa Indonesia," kbbi.web.id, KBBI, t.t., diakses 20 Maret 2020.

${ }^{7}$ Rasid Rachman, Pengantar Sejarah Liturgi (Tangerang: Bintang Fajar, 1999), 122.
} 
menyesuaikan dengan budaya lain) tidak memadai, maka konsep kontekstualisasi diangkat untuk mengusahakan indegenisasi teologi dengan menerima input proses sekularitas, teknologi, serta pergumulan demi Hak Asasi Manusia (HAM) yang merupakan "The Historical Moment of Nations in the Third World" membicarakan kontekstualisasi, tentunya juga akan membahas teologia kontekstual. Terkait tentang bagaimana berteologia dalam konteks setempat, sehingga berita Injil dapat disampaikan. Akan tetapi, penginjilan kontekstual sudah diterapkan sejak zaman para Rasul. Seperti telah penulis sampaikan di atas, Yohanes berusaha menggunakan konteks masyarakat setempat (dalam hal ini Helenis), dengan menggunakan istilah logos, untuk memperkenalkan Yesus Kristus. Charles Taber menjelaskan mengenai kontekstualisasi sebagai berikut:

Usaha memahami dengan serius setiap konteks kelompok manusia dengan segala dimensi budaya, agama, sosial, politik, ekonomi, untuk menemukan bagaimana Injil ataupun cara Injil berbicara kepada mereka. Injil dibawa, diberi bungkusan yang kontekstual. ${ }^{9}$

Penginjilan kontekstual terus mengalami perkembangan dari masa ke masa.Upaya menjadikan semua bangsa murid Kristus terus digerakan dengan menjangkau setiap suku yang ada. Di Indonesia terdapat 750 aneka ragam suku yang berada dari Sabang-Marauke. Menurut data yang dirilis oleh PJRN sebanyak 125 suku di Indonesia, hidup dalam kegelapan dan belum mendengar Injil. ${ }^{10}$

Suku-suku tersebut merupakan unreached people groups atau kelompok suku terabaikan yang perlu dijangkau dan dilayani. Menurut data IPN (Indonesia Pelangi Nusantara), disebut unreached people groups atau suku terabaikan karena

8 Imanuel Sukardi, "Prinsip-Prinsip Kontekstualisasi'," www.misi.sabda.org, E-Misi, 2012, http:// misi. sabda. org / prinsip-prinsip-kontekstualisasi.

${ }^{9}$ Charles R. Taber, "Contextualizazion: Indigenization and/or Transformation," www.misi.sabda.org, E-Misi, diakses 25 September 2020, http://misi.sabda.org/Contextualizazion: Indigenization and/or Transformation.

10 N N, "Presentasi PJRN," 2010. 
jumlah populasinya lebih dari 10.000 dan jumlah orang Kristen atau orang percayanya masih kurang dari atau sama dengan $1 \% .{ }^{11}$ Artinya, jika populasi orang percaya belum sampai pada angka $1 \%$ sudah pasti gereja suku belum terbentuk dengan demikian perlu untuk diayani. Kendatipun demikian, melayani ataupun menjangkau suku terabaikan ini bukanlah pekerjaan yang mudah. Ada banyak tantangan dan hambatan yang berkaitan dengan karakteristik dari setiap suku yang ada. Secara umum, kendala yang sering dihadapi adalah, pada pola pendekatan.

Dalam upaya menjangkau suku terabaikan ada beberapa pola pendekatan yang digunakan. Dalam penulisan ini, penulis mengambil contoh bagaimana para pekerja lapangan dalam melayani dan mendekati salah satu kelompok unreached people groups. Salah satu upaya yang pernah dilakukan adalah dengan membangun taman bacaan masyarakat. Kebutuhan pendidikan non formal di tengah komunitas masyarakat suku terabaikan, menjadi jembatan yang cukup efektif untuk mendekati komunitas suku terabaikan atau unreached people grups tersebut. Dengan membangun masyarakat cinta baca, melalui kelompok baca dan disaat bersamaan juga bersaksi menyampaikan Kabar Baik.

Metode ini awalnya cukup efektif, ada banyak desa dan komunitas masyarakat suku terabaikan yang bisa dikumpulkan dan menerima "orang asing" menjadi sahabat mereka, tertarik dengan taman bacaan masyarakat dan pos-pos baca. Akan tetapi, ketika masuk kepada inti ataupun tujan utama yaitu memberitakan kabar baik, selalu menemukan kendala atau hambatan.

${ }^{11}$ N N, "Indonesia Profil Suku-suku Yang Terabaikan" (IPN Indonesia, 2010), i. 
Dari tahun ke tahun upaya penjangkauan terus diupayakan, berbagai metode dan cara baik konvesional maupun yang modern juga terus digunakan demi untuk melayani suku terabaikan. Hingga saat ini, hasil yang didapat masih jauh dari apa yang diharapkan. Penulis melihat, pola pendekatan, pemahaman budaya lokal masih menjadi tantangan dalam penjangkauan. Pola pendekatan yang salah dan kurangnya pemahaman karakteristik budaya dari salah satu suku tersebut berakibat pada ketidaknyamanan orang yang dilayani.

\section{METODE PENELITIAN}

Tulisan ini merupakan sebuah kajian yang menggunakan pendekatan kualitatif pada teks Alkitab, adapun teks Alkitab yang dimaksud yakni 1Korintus 9: 19-23. Metode yang digunakan yaitu metode deskriptif, metode ini menggambarkan dengan jelas bagaimana cara dan setrategi rasul Paulus dalam melakukan pekabaran Injil lintas budaya. Selain itu, penulis juga menggunakan studi pustaka untuk mendapatkan informasi-informasi mengenai pekabaran Injil lintas budaya yang dilakukan oleh rasul Paulus.

\section{HASIL}

Penelitian ini untuk memberikan pemaparan secara deskriptif bagaimana prinsip-prinsip dalam melayani unreach people groups. Selain itu hasil dari penelitian ini untuk menunjukkan bahwa mandat misi dalam Amanat Agung adalah prinsip teologis yang relevan. Penelitian ini untuk memperlihatkan adanya problematika dalam penjangkauan unreach people groups, baik itu dari segi pemikiran teologis, praktis dan motivasi. Sehingga hasil dari tulisan ini akan memberikan solusi yang tepat bagaimana melaksanakan Amanat Agung dalam konteks unreach people group. 


\section{PEMBAHASAN}

Memberitakan Injil merupakan Amanat Agung yang Tuhan Yesus berikan dan mandatkan kepada setiap orang percaya. Matius 28: 18-20 mencatat bahwa Tuhan Yesus memerintahkan untuk menjadikan semua bangsa murid-Nya. Merujuk kepada teks dalam Injil Matius 28: 18-20, sangatlah jelas bahwa Tuhan Yesus menghendaki setiap suku, kaum dan bahasa menjadi pengikutnya. Kata Yunani etnos dalam Matius 28: 19-20 menunjuk kepada etnis dan suku. Oleh karena itu, setiap orang perlu mendengarkan berita Injil. Perihal Amanat Agung ini Shipman menulis:

Amanat Agung adalah memaparkan rencana penginjilan dan perintisan jemaat-jemaat, serta menyelesaikan pelayanan penebusan Yesus Kristus, yang dimungkinkan oleh darah-Nya sendiri dan dinyatakan melalui karya rasul. Demikianlah Amanat Agung adalah cetak biru bagi pelaksanaan penginjilan oleh para rasul dan orang modern. ${ }^{12}$

Alkitab mencatat tekanan sebanyak lima kali penyampaian Amanat Agung. Dengan demikian tujuan Amanat Agung adalah untuk menjadikan semua bangsa pengikut Yesus melalui tanggung jawab (Yoh. 20: 19-23) untuk mengabarkan Injil (Luk. 24: 44-49) kepada setiap orang (Mrk. 16: 15-16) dan setiap tempat, dikuasai oleh Roh Kudus (Kis. 1: 8). ${ }^{13}$

Melihat Amanat Agung yaitu tugas memberitakan Injil atau kabar baik kepada setiap suku, maka perlu kerelaan untuk melakukannya. Para rasul telah terlebih dahulu memberikan teladan bagaimana mereka memberitakan Injil, dengan kerelaan sampai kesetiap tempat bahkan mati syahid, ini membuktikan bahwa Injil sungguh satu-satunya jalan keselamatan. ${ }^{14}$ Perlu kerelaan dan

\footnotetext{
12 Michael K. Shipman, Amat Agung: Karya Kerasulan Kuno dan Kini (Rahayu Group, 2011), 67.

${ }^{13}$ Shipman, 69.

14 Shipman, 29.
} 
kerendahan hati bahkan strategi agar Injil dapat sampai kepada setiap suku bangsa dan bahasa sehingga mereka beroleh keselamatan di dalam Yesus Kristus. Pemberitaan Injil lintas budaya juga diperlukan agar dapat memahami dan menyampaikan berita keselamatan. Melalui analisa homiletik, penulis menemukan tiga karakteristik penginjil lintas budaya atau kontekstual, yang terdapat dalam setrategi Paulus, dan dapat diuraikan sebagai berikut:

\section{Rela Menghambakan Diri (1Kor. 9 :19)}

Kata hamba yang dipakai dalam konteks ini menggunakan istilah


ini merupakan kata kerja indicative aorist active orang pertama tunggal maksudnya bahwa sesuatu pernah terjadi atau pernah dilakukan sehingga memiliki pengertian menghamba. Berdasarkan data leksikal, kata edulosa yang merupakan kata kerja indicative aorist active, dapat dimengerti bahwa "menghamba" merupakan tindakan yang dilakukan dengan sengaja. Dalam hal ini, Paulus melakukannya dengan sadar dan sukarela menghamba demi untuk memenangkan jiwa. Melihat dari akar kata Yunaninya, doulos memiliki pengertian sebagai seorang hamba atau budak, Alkitab terjemahan versi KJV menerjemahkan dengan kata "servant" pelayan yang tidak mempunyai hak. Jadi secara sadar menjadikan dirinya pelayan yang tidak mempunyai hak, demi untuk memenangkan jiwa.

Dalam paragraf ini, Paulus mengalihkan topik pembicaraannya namun masih berkaitan. Sebelumnya ia menyampaikan mengenai haknya sebagai seorang rasul, bahkan membela haknya sebagai seorang rasul meskipun ia sendiri tidak meminta haknya untuk didukung dalam hal finansial. Dan setelah itu, ia berbicara 
mengenai melepaskan hak budayanya untuk menjangkau orang lain. Terkait akan hal ini, Grant Richison menuliskan:

Paulus sekarang beralih dari subjek melepaskan haknya atas dukungan finansial untuk melepaskan hak-hak budaya. Enam kali dalam paragraf ini Paulus menyatakan keinginannya untuk menjangkau yang terhilang. Dia menjangkau yang terhilang dengan mengadaptasi metodenya sesuai dengan kelompok yang dia coba jangkau. Ini adalah prinsip kemanfaatan. ${ }^{15}$

Menurut Richison, Paulus telah menyampaikan tujuannya untuk memenangkan kelompok lain, sekaligus menyampaikan strategi penginjilannya untuk memenangkan kelompok tersebut. Strategi pertama yang ia sampaikan dalam ayat 19 adalah bahwa rela menjadikan dirinya hamba. Sementara itu menurut Parshall:

Ini adalah suatu kerendahan hati yang sempurna. Gagasan seperti ini membawa Paulus, sebagai seorang Yahudi yang sangat terpelajar, memberitakan Kristus dengan penuh kerendahan hati kepada seorang budak yang melarikan diri, yang kelak dianggapnya sebagai seorang sahabat (Filemon 1: 16). Dalam peran sebagai seorang hamba, Paulus menanggung penderitaan, kesesakaan, deraan, pemenjaraan, kekacauan, jerih payah, kurang tidur, dan kelaparan (2Kor. 6: 4-5). ${ }^{16}$

Meskipun ia bebas atas semua orang, ia telah menjadikan dirinya hamba untuk semua orang. Ungkapan "I made myself servant" dalam KJV, memiliki makna memberikan diri sepenuhnya untuk melayani. Richison menjelaskan bebas yang dimaksud Paulus sebagai berikut:

Paul was free in two areas: as a Roman citizen he was a free man, and as a Christian he had freedom in Christ (Gal 5: 1) so he was free from Jewish laws, for example. He waived his freedom to reach people with the gospel. Since Paul did not receive remuneration for his ministry, he was free from

15 Grant Richison, "1Corinthians 9: 19-23," www.versebyversecomentary.com, Verse By Verse, 10 Desember 2002, https://www.versebyversecomentary.com/1Corinthians9:19-23/.

16 Phill Parshal, "Penginjilan Muslim: Pendekatan-pendekatan Kontemporer Pada Kontekstualisasi," info@ikut-isa.org, ikut-isa, 2005, https://info@ikut-isa.org/Penginjilan Muslim: Pendekatanpendekatan Kontemporer Pada Kontekstualisasi. 
criticism from those without Christ. Although he was free in Christ, he made himself a slave to all in method. ${ }^{17}$

Paulus melepaskan haknya sebagai orang bebas dengan menjadikan dirinya hamba untuk sebuah tujuan yaitu menjangkau orang lain yang belum percaya. Rasul Paulus telah menjadikan dirinya sendiri sebagai teladan dalam menjangkau orang yang belum percaya. Dalam memberitakan kabar baik kepada kelompok orang yang belum percaya, diperlukan kerelaan diri untuk menjadikan diri sendiri sebagai hamba. Ini merupakan strategi awal yang Paulus lakukan agar dapat mendekati dan menjangkau orang lain. Ia mengatakan 'aku menjadikan diriku hamba' ia telah melepaskan haknya supaya dapat diterima oleh setiap orang. Seorang pemberita Injil, secara khusus pemberita Injil lintas budaya seharusnya mengikuti teladan rasul Paulus yang rela menjadi hamba, melepaskan haknya untuk memenangkan orang lain. Sejarah gereja Indonesia mencatat bahwa pada 14 Mei 1862 ada seorang yang bernama Ludwig I. Nomennsen yang rela meninggalkan kemajuan dan kenyamanan di negaranya untuk pergi ke Sumatera bagian utara demi memberitakan Injil. ${ }^{18}$ Nomennsen pada akhirnya dapat memenangkan suku Batak, dengan rela 'menjadi hamba untuk orang-orang batak' demi dapat memenangkan mereka. Sejarah gereja Asia juga mencatat bahwa ada William Carey, seorang Baptis dari Inggris yang rela meninggalkan Inggris, negara yang sudah cukup maju pada waktu itu, untuk pergi kepada orang India agar dapat memenangkan orang India, dan ia menjadi misionaris pertama yang datang ke India pada tahun $1792 .{ }^{19}$ Tanpa merelakan dirinya menjadi hamba, tidaklah mungkin Carey bersedia meninggalkan Inggris dan berada di antara

17 Richison, "1Corinthians 9: 19-23." 1987), 198-199.

18 F.D. Willem, Riwayat Singkat Tokoh-Tokoh Dalam Sejara Gereja (Jakarta: BPK Gunung Mulia, ${ }^{19}$ Anne Ruck, Sejarah Gereja Asia (Jakarta: BPK Gunung Mulia, 2008), 156-157. 
orang-orang India. Tantangan sebagai pemberita Injil tidaklah mudah, Carey mengalami itu semua, namun oleh karena panggilan dan kesediaanya menjadikan dirinya hamba membuat ia dapat melalui semuanya itu tanpa kenal menyerah. ${ }^{20}$

Pemberitaan Injil pada masa kinipun tetap memerlukan kerelaan menjadikan diri seorang hamba. Keteladanan yang diberikan oleh rasul Paulus dalam penjangkauan masih berlaku dari waktu ke waktu. Sebuah strategi yang sangat baik menjadikan diri hamba untuk semua orang untuk memenangkan sebanyak mungkin. Menjadikan diri hamba bukan dalam pengertian tunduk dan dapat diatur oleh semua orang atau pun tidak memiliki prinsip. Menjadikan diri hamba di sini dalam pengertian meninggalkan atau melepaskan hak-haknya demi pemberitaan Injil seperti yang telah dilakukan Paulus, juga Nomennsen dan William Carey dalam era yang berbeda. Tak jarang pada masa kini gerakan penjangkauan lintas budaya kurang berhasil karena para utusan Injil enggan melepaskan hak-haknya dan menjadikan diri hamba bagi semua orang.

\section{Rela Menyesuaikan Diri (1Kor. 9: 20-21)}

Ini adalah strategi lainnya yang dipakai Paulus dalam menjangkau orang bagi Kristus dan berkaitan dengan strategi sebelumnya. Ungkapan Paulus

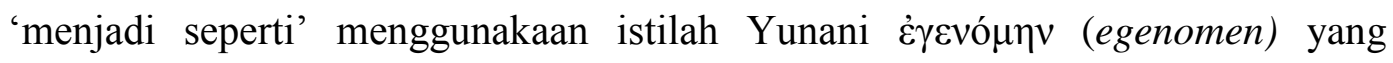
diterjemahkan became as dalam KJV. Dalam tenses Yunani ini merupakan kata kerja indicative aorist midlle orang pertama tunggal, yang menerangkan peristiwa ini pernah terjadi. Kata ini berasal dari kata dasar ginomai memiliki banyak terjemahan berdasarkan konteksnya. ${ }^{21}$ Dalam paragraf ini, kata ini dipahami dengan diterjemahkan 'menjadi seperti' menyamai atau menyesuaikan diri. Dalam

\footnotetext{
20 Ruck, 156-157.

${ }^{21}$ Gingrich, Bible Works, versi 8, CD ROM, 1 Korintus 9:20, ginomai, Gingrich Gree Lexicon, t.t., diakses 4 Desember 2020.
} 
kerelaannya menjadikan diri hamba, Paulus juga mengajarkan pola mendekatan agar berita Injill dapat disampaikan dengan pasti. Ia menyesuaikan dirinya kepada siapa ia menyampaikan kabar baik atau berita Injil.

Dengan metode atau strategi ini apakah Paulus seorang munafik ataupun 'bunglon' yang tidak punya prinsip? Mengenai hal ini, Wiersbe menulis:

Apakah Paulus bertingkah laku tidak konsekuen? Tentu saja tidak. Ia semata-mata menyesuaikan pendekatannya terhadap berbagai kelompok. Apabila anda membaca khotbah-khotbah dalam kitab Kisah Para rasul, Anda dapat melihat penyesuaiannya yang bijaksana ini. Apabila ia berkhotbah kepada orang-orang Yahudi, ia memulai dengan kehidupan nenek moyang dalam Perjanjian Lama. Tetapi, apabila ia berkhotbah kepada orang-orang non-Yahudi, ia memulai dengan Allah Sang Pencipta. Paulus tidak memiliki 'persediaan khotbah' untuk segala kesempatan. ${ }^{22}$

Sementara itu, Peter Salemi memberikan komentarnya sebagai berikut:

Paul acted like something he was not. Some people might call that hypocritical or deceptive; Paul calls it part of his evangelistic strategy... For someone to act like a Gentile, they would eat foods that Jews could not, and they would not observe the Sabbath... When Paul was with Jews, he kept the old covenant food laws and weekly and annual Sabbaths. When he was with the Gentiles, he did not. He sometimes acted differently from what he believed. ${ }^{23}$

Paulus bukan sedang tidak konsekuen, ungkapan menjadi seperti ini merupakan strategi yang sedang digunakan oleh Paulus, yaitu menyesuaikan diri untuk melakukan pendekatan supaya dapat memberitakan Injil.

Patut diperhatikan juga bahwa Tuhan Yesus juga melakukan pendekatan yang sama kepada Nikodemus seorang keturunan bangsawan Yahudi Ia berbicara tentang kelahiran baru (Yoh. 3), sedang kepada perempuan Samaria, Ia berbicara tentang air hidup (Yoh. 4). Tuhan Yesus sungguh pandai dan dapat menyesuaikan diri, dan Paulus mengikuti teladan-Nya. Tuhan Yesus dan Paulus memiliki

22 Wiersbie Warren, Hikmat Dalam Kristus (Bandung: Kalam Hidup, 2001), 128.

23 Wiersbie Salemi, "Does 1 Corinthians 9:19-23 mean Paul did not keep God's Law," www.BritishIsrael.ca, British Israel, diakses 4 Februari 2020, https://www.British-Israel.ca/Does 1 Corinthians 9:19-23 mean Paul did not keep God's Law/. 
"formula Penginjilan" yang selalu sesuai untuk setiap keadaan. ${ }^{24}$ Dapat dibayangkan bagaimana jadinya jika Paulus tidak menyesuaikan ketika ia berbicara di Athena (Kis 17: 16-34). Ketika Paulus menyampaikan Injil kepada orang di Athena, yang notabene bukan orang Yahudi, tidaklah mungkin ia akan mengawali pemberitaan Injilnya dengan cerita nenek moyang Israel dan Hukum Taurat. Sudah pasti mereka tidak paham, namun dengan sangat cerdik Paulus mendekati mereka dengan cerita kebiasaan mereka yang memiliki banyak patung dewa-dewa di kotanya dan terdapat tulisan 'kepada Allah yang tidak dikenal'. Melalui hal itu, Paulus menyampaikan Allah sebagai pencipta langit dan bumi, hingga pada akhirnya Paulus menyampaikan berita Injil kepada orang yang ada di areopagus. Dalam penginjilan lintas budaya, strategi seperti Paulus untuk menjadi seperti atau menyesuaikan sangat diperlukan guna Injil sampai kepada pendengar. Dengan strategi Paulus ini bukan berarti menggunakan standar ganda, namun ia mencari titik temu sebagai cara untuk mendekati sehingga Injil dapat diberitakan.

Strategi yang Tuhan Yesus dan rasul Paulus lakukan dalam pendekatan untuk menyampaikan berita Injil terus dikembangkan oleh para ahli penginjilan ataupun misiolog, hingga muncul istilah penginjilan kontekstual. Istilah pengiinjilan kontekstual ini digunakan untuk mengacu kepada penginjilan lintas budaya dan tradisi. Pada misionaris modern ada seorang William Carey yang menyesuaikan dirinya dengan orang-orang India, belajar budaya dan bahasa India agar dapat mendekati orang India. ${ }^{25}$ Apa jadinya jika Carey menggunakan bahasa dan budaya Eropa untuk mendekati orang-orang India, tentu akan sangat sulit untuk diterima karena ketidakpahaman. Sejarah mencatat dengan 'menjadi 
seperti' atau dengan menyesuaikan, Carey dapat menerjemahkan Alkitab dalam bahasa setempat dan Injil dapat disampaikan dan dipahami oleh masyarakat asli India, sehingga Carey dapat membuka pos-pos Penginjilan. ${ }^{26}$ Selain itu juga, Carey juga bisa menghapuskan tradisi sesat Sati yaitu pembakaran janda-janda yang ditinggal mati oleh suaminya. ${ }^{27}$

Strategi penginjilan ini relevan disegala waktu, Tuhan Yesus melakukannya dalam pendekatan kepada Nikodemus dan perempuan Samaria, Paulus juga melakukan hal yang sama ketika memberitakan Injil kepada kelompok bukan Yahudi. Menyesuaikan diri, dengan mencari pemahaman yang sama sebagai jembatan untuk menyampaikan berita Injil. Jika melihat apa yang dilakukan oleh Tuhan Yesus maupun rasul Paulus dalam memberitakan Injil, sesungguhnya tidak alasan bagi Misionaris atau penginjil untuk berprilaku ethnosentris.

Ethnosentris merupakan sikap yang menganggap bahwa etnisnya yang paling baik dan yang lain harus mengikutinya. Parshal berpendapat bahwa, Misionaris-misionaris yang amat ethnosentris ini yakin sepenuhnya bahwa apa yang baik untuk Eropa, juga baik untuk seluruh dunia. Akibatnya ada terjadi sebuah komunitas Kristen yang "aneh" yang menjadi bahan tertawaan orangorang mayoritas Indonesia. ${ }^{28}$ Apa yang disampaikan oleh Parshall merupakan kegagalan dalam memahami atau menyesuaikan diri dalam pendekatan terhadap kelompok mayoritas yang berbudaya Indonesia. Ketika tidak menyesuaikan maka tidak dapat memahami dan menjadi sama.

26 Ruck, 156-157.

${ }^{27}$ Michael Colins dan Matthew A. Price, Milenium The Story Of Christianity (Yogyakarta: Kanisius, 2006), 182-183.

28 Parshal, "Penginjilan Muslim: Pendekatan-pendekatan Kontemporer Pada Kontekstualisasi" 48. 
Dalam strategi menyesuaikan diri atau menjadi seperti bukan saja tentang menemukan titik temu untuk dipahami seperti yang Paulus lakukan ketika memberitakan Injil di Athena, atau Tuhan Yesus yang memberitakan Injil kepada perempuan Samaria. Akan tetapi, pemberita injil juga perlu untuk memahami bahasa dan budaya kelompok yang akan dilayani. Bahasa merupakan media untuk menyampaikan pesan, ketika bahasa yang digunakan tidak bisa dipahami, maka pesan tidak akan sampai kepada pendengar. Salah satu keberhasilan William Carey menyampaikan berita Injil kepada orang-orang India karena ia memahami bahasa dan budaya setempat. Tidak sedikit salah satu kegagalan dalam penginjilan kontekstual adalah karena ke engganan mempelajari bahasa dan budaya atau tidak rela menyesuaikan, dan cenderung membawa budaya asal dan ornamenornamennya.

Dalam startegi dan metode pemberitaan Injil, apa yang dilakukan Paulus dengan ungkapan 'menjadi seperti' atau menyesuaikan diri ini sering disebut dengan istilah penginjilan kontekstual. Memberitakan Injil dalam bahasa dan budaya setempat, tanpa merubah isi berita Injil. Ketika berbicara penginjilan kontekstual mungkin saja akan ada hal-hal kontroversial. Mengenai hal ini Edstezer berpendapat:

Although it is sometimes controversial, contextualization remains a critical component of effective Gospel communication. The New Testament models the importance of healthy contextualization, and the history of Christian missions displays the need for contextualization. ${ }^{29}$

Tuhan Yesus memberikan teladan pendekatan dalam penginjilan lintas budaya dengan sangat sempurna, ketika dia berbicara kepada Nikodemus (Yoh. 3) maupun ketika menyampaikan Kabar Baik kepada perempuan Samaria (Yoh. 4).

${ }^{29}$ Edstezar, "What Is Contextualization," t.t., diakses 4 April 2020. 
Dalam pelayanan memberitakan Injil Kristus, sebagai seorang rasul Paulus juga dapat menyesuaikan diri dengan baik. Kepada orang Yahudi maupun bukan orang Yahudi, selalu menjembatani dengan suatu hal yang dapat dipahami dan juga mampu memahami.

\section{Memiliki Visi Memenangkan Jiwa (1Kor. 9: 21-22)}

Visi adalah apa yang diimpikan, diciptakan, diharapkan untuk dicapai oleh pemimpin dan para pengikutnya. Visi itu akan menarik pemimpin dan pengikutnya ke arah masa depan. ${ }^{30}$ Dalam memberitakan Injil, penginjil ataupun misionaris haruslah memiliki visi untuk tujuan yang akan dicapai, yaitu memenangkan jiwa. Seperti penulis sampaikan di atas, enam kali dalam paragraf ini Paulus menyatakan keinginannya untuk menjangkau yang terhilang. Dia mencapai yang terhilang dengan mengadaptasi metodenya sesuai dengan kelompok yang dia coba jangkau. ${ }^{31}$ Enam kali pernyataannya yang menunjukkan keinginannya untuk menjangkau yang terhilang, menggunakan kata Yunani yang berbeda. Lima kali Paulus menggunakan kata kerdaino (memenangkan) dengan perubahan bentuknya dan terakhir ia menggunakan kata sozo (menyelamatkan). Johnson menjelaskan menyelamatkan lebih kuat maknanya daripada memenangkan, tapi bukan berarti mengambil atau mendahului peran Allah. ${ }^{32}$ Kata ini juga dapat dimaknai sebagai keinginan Paulus yang kuat untuk membawa yang terlihang kepada keselamatan di dalam Yesus Kristus. Paulus sebagai seorang rasul memiliki visi dan tujuan yang sangat jelas yaitu memenangkan jiwa,

30 Stevri I. Lumintang, Theologia Kepemimpinan Kristen: Theokrasi Di Tengah Sekularisasi Gereja Masa Kini (Jakarta: Geneva Insani Indonesia, 2015), 284.

${ }^{31}$ Richison, "1Corinthians 9: 19-23."

32 Lewis Johnson, "1 Korintus 9: 22," dalam Tafsiran Alkitab Wycliffe, ed. oleh Charles F. Pfeiffer dan Everett F. Harrison, vol. 3 (Malang: Gandum Mas, t.t.), 629. 
membawa orang belum percaya kepada keselamatan di dalam Tuhan Yesus Kristus.

Dalam teori kepemimpinan, seorang pemimpin haruslah memiliki visi yaitu keampuan untuk meilhat kedepan, sehingga memiliki arah dan tujuan yang jelas. Menurut Desi Anwar, visi merupakan kemampuan untuk melihat pada inti, wawasan pandangan ke depan. ${ }^{33}$ Visi menolong untuk membuat tujuan yang akan dicapai, sekaligus membantu menetapkan target. Rasul Paulus memiliki visi agar sedapat mungkin orang Yahudi ataupun bukan Yahudi dimenangkan atau diselamatkan. Untuk mencapai tujuan tersebut, Paulus bertindak memberitakan Injil kepada mereka dengan strategi. Kembali kepada William Carey, seorang utusan Injil asal Inggris, memiliki visi memenangkan orang-orang India, dan benar-benar menyesuaikan diri, beradaptasi dengan orang-orang di India, sehingga dapat bertahan, memenangkan orang India, dan mendirikan gereja. Seorang pekabar injil pun juga harus memiliki visi untuk mencapai tujuannya, sehingga jelas yang menjadi gol penginjilannya.

Ketika memiliki visi atau gol dari sebuah tujuan, maka itu dapat membuat bertahan. Paulus telah memberikan teladan yang sangat luar biasa, sebagai seorang rasul ia memiliki tujuan, untuk memenangkan yang terhilang. Kemanapun ia pergi, selalu ada beban dihatinya untuk memberitakan Injil, baik kepada orang Yahudi maupun orang bukan Yahudi. Dalam paragraf ini, secara konsisten menyatakan tujuannya untuk memenangkan dan menyelamatkan setiap orang yang belum percaya.

${ }^{33}$ Dessy Anwar, Kamus Lengkap Bahasa Indonesia (Surabaya: Karya Abditama, 2001), 589. 
Pada prinsipnya, sangat bijaksana mengakui bahwa semua orang berbeda. Oleh sebab itu, tidak hanya ada satu cara untuk memenangkan orang bagi Kristus, karena semuanya berbeda. Menggunakan jenis 'umpan' yang tepat untuk jenis ikan yang tepat, untuk menjangkau yang terhilang di tanah mereka. Mendatangi orang-orang di tempat tujuan mereka dan mendekati mereka di sisi mereka yang dapat dijangkau. Dengan cara menjalin hubungan dengan mereka sehingga mereka dapat mendengar Injil tanpa beban dan tekanan.

Prinsip menyesuaikan atau menjadi seperti bagi mereka yang terhilang sehingga dapat memenangkan mereka adalah prinsip kasih bagi yang terhilang. Penginjilan itu kadang-kadang menyakitkan, tetapi ketika dapat melepaskan hakhak dan memberi diri untuk menjadi berkat, maka akan menemukan berkat dalam memberi lebih dari pada menerima. Hidup dalam cahaya kekekalan selalu lebih memuaskan daripada hidup untuk diri sendiri. Perlu memperhatikan satu hal yaitu, peringatan tentang prinsip menyesuaikan diri kita sendiri kepada orang-orang untuk memenangkan mereka bagi Kristus. Idenya bukanlah "Ketika di Roma, melakukan seperti yang dilakukan orang Romawi." Beberapa menggunakan kebebasan mereka sebagai alasan untuk menyenangkan diri mereka dalam kehidupan. Itu adalah kompromi dari kesenangan diri sendiri, dan bukanlah strategi. Firman Tuhan merupakan standar tertinggi, tetapi merelakan menjadi hamba dan melepaskan hak demi orang lain dimenangkan adalah sebuah metode atau cara.

\section{KESIMPULAN}

Memberitakan kabar baik atau penginjilan, merupakan tugas semua orang percaya. Strategi dan metode diperlukan hanya untuk memastikan berita injil 
diterima oleh orang yang mendengarkan. Penulis menyampaikan tiga karakteristik pekabar injil yang harus dipahami dan diimplementasikan dalam pekabaran injil terlebih dalam konteks lintas budaya.

Pekabaran injil merupakan pekerjaan yang besar, perlu kerelaan yang sungguh dalam mengerjakannya. Rela menjadi hamba, dengan menghambakan diri, dengan melepaskan haknya secara sadar, supaya berita injil dapat disampaikan. Menghambakan diri untuk melayani memerlukan kerelaan, bukan dengan tekanan. Ketika rela dan menyadari dirinya sebagai hamba seperti halnya rasul Paulus, maka tanpa perintah lembaga atau pun organisasi pastilah tetap akan memberitakan injil. Kerelaan menyesuaikan diri, menjadi sama bukan berarti tidak mempunyai pendirian yang jelas. Paulus tidak pernah merubah isi berita, tetap memberitakan bahwa Yesus Kristus adalah Tuhan dan juru selamat yang telah mati dan bangkit naik ke surga. Yang berubah adalah pola pendekatan yang dilakukannya, yaitu dengan menyesuaikan diri. Dalam menyesuaikan itu meliputi pemahaman budaya, bahasa dan tradisi. Sehingga, dengan pemahaman tersebut, berita injil dapat disampaikan dengan efektif.

Selayaknya pemberita injil haruslah memiliki visi untuk memenangkan jiiwa. Apapun strategi yang digunakan, ketika tidak memiliki visi yang jelas, maka sulit untuk berhasil. Ketika rasul Paulus mengungkapkan sebuah metode atau cara, disaat bersamaan juga ia menyampaikan sasaran yang akan dicapainya, yaitu "supaya dapat memenangkan." Pada prinsipnya, injil harus diberitakan kepada setiap orang, karena itu merupakan Amanat Agung yang diberikan kepada orang percaya. Kapan saja dimana saja, injil harus diberitakan kepada setiap suku kaum dan bahasa. 


\section{DAFTAR PUSTAKA}

Anwar, Dessy. Kamus Lengkap Bahasa Indonesia. Surabaya: Karya Abditama, 2001.

Colins, Michael, dan Matthew A. Price. Milenium The Story Of Christianity. Yogyakarta: Kanisius, 2006.

Edstezar. "What Is Contextualization," t.t. Diakses 4 April 2020.

Friberg. Bible Work (versi 8). CD ROM, Inggris. Analytical Greek Lexicon, t.t. Diakses 4 Maret 2020.

Gingrich. Bible Works (versi 8). CD ROM. 1 Korintus 9:20, ginomai, Gingrich Gree Lexicon, t.t. Diakses 4 Desember 2020.

Johnson, Lewis. "1 Korintus 9: 22." Dalam Tafsiran Alkitab Wycliffe, disunting oleh Charles F. Pfeiffer dan Everett F. Harrison, 3:629. Malang: Gandum Mas, t.t.

Lumintang, Stevri I. Theologia Kepemimpinan Kristen: Theokrasi Di Tengah Sekularisasi Gereja Masa Kini. Jakarta: Geneva Insani Indonesia, 2015.

N, N. “Indonesia Profil Suku-suku Yang Terabaikan,” i. IPN Indonesia, 2010. . "Kamus Besar Bahasa Indonesia.” Kbbi.web.id. KBBI, t.t. Diakses 20 Maret 2020.

—. "Presentasi PJRN," 2010.

Parshal, Phill. "Penginjilan Muslim: Pendekatan-pendekatan Kontemporer Pada Kontekstualisasi.”Info@ikut-isa.org. ikut-isa, 2005. https://info@ikutisa.org/Penginjilan Muslim: Pendekatan-pendekatan Kontemporer Pada Kontekstualisasi.

Rachman, Rasid. Pengantar Sejarah Liturgi. Tangerang: Bintang Fajar, 1999.

Richison, Grant. "1Corinthians 9: 19-23." Www.versebyversecomentary.com. $\begin{array}{lllll}\text { Verse } & \text { By } & \text { Verse, } & 10 & \text { Desember }\end{array}$ https:/www.versebyversecomentary.com/1Corinthians9:19-23/.

Ruck, Anne. Sejarah Gereja Asia. Jakarta: BPK Gunung Mulia, 2008.

Salemi, Wiersbie. "Does 1 Corinthians 9:19-23 mean Paul did not keep God's Law." Www.British-Israel.ca. British Israel. Diakses 4 Februari 2020. https://www.British-Israel.ca/Does 1 Corinthians 9:19-23 mean Paul did not keep God's Law/.

Shipman, Michael K. Amat Agung: Karya Kerasulan Kuno dan Kini. Rahayu Group, 2011. 
Sukardi, Imanuel. Berkat-Berkat Surat Roma. Surakarta: STT Berita Hidup, 2011.

—_ "Prinsip-Prinsip Kontekstualisasi'.” Www.misi.sabda.org. E-Misi, 2012. http:// misi. sabda. org / prinsip-prinsip-kontekstualisasi.

Taber, Charles R. "Contextualizazion: Indigenization and/or Transformation." Www.misi.sabda.org. E-Misi. Diakses 25 September 2020. http://misi.sabda.org/Contextualizazion: Indigenization and/or Transformation.

Tomatala, Yakub. Penginjilan Masa Kini 1. Malang: Gandum Mas, 1997.

Waharman, Waharman. "Studi Eksegetis Peranan Roh Kudus Dalam Penginjilan Berdasarkan Injil Yohanes 16:4b-15." Manna Rafflesia 6, no. 1 (31 Oktober 2019): 36-52. https://doi.org/10.38091/man_raf.v6i1.109.

Warren, Wiersbie. Hikmat Dalam Kristus. Bandung: Kalam Hidup, 2001.

Wiersbe, Warren W. The Bible Exposition Commentary; An Exposition of The new Testament Comprising the Entire "BE” Series. Illionis: Victor Books, 1989.

Willem, F.D. Riwayat Singkat Tokoh-Tokoh Dalam Sejara Gereja. Jakarta: BPK Gunung Mulia, 1987. 